\title{
A new method of calculating charged deep level defects density in doped semiconductors from the band offsets of MIS device interfaces
}

\author{
Ravi Kumar Chanana \\ Department of Electrical and Electronics Engineering, Galgotia's College of Engineering and Technology, \\ Affiliated to Uttar Pradesh Technical University, Lucknow, 1, Institutional Area, Knowledge Park-II, Greater \\ Noida - 201306 India.
}

Abstract: Band offsets of the semiconductor/Insulator interfaces are utilized to determine charged deep level defects density in doped single and compound semiconductors. This method is new and is able to determine very low defects densities, which are not possible to be determined by other existing techniques. A modified equation for the intrinsic Fermi level in semiconductors is formulated by including the term due to defects density.

Keywords: Deep-level defects, metal-insulator-semiconductor, charge neutrality, Diamond

\section{Introduction}

Point defects are zero-dimensional defects in semiconductor crystals. They can physically be a vacancy (Schottky defect), an interstitial, a vacancy-interstitial pair (Frenkel), extrinsic point defect as an impurity atom, or a split interstitial defect. In a compound semiconductor such as GaAs, the presence of two types of atoms opens the possibility of having a Ga atom in place of an As atom. This type of defect is called a Ga antisite defect. There could also be complexes of this defect with other native or extrinsic point defects such as a antisite-vacancy complex. Point defects are electrically active defects as they can be in more than one charge state as a donor or acceptor defect. As a donor, the defect is neutral when occupied by the electron and is positive after donating an electron. In the same way, the acceptor is negative when occupied by electron and becomes neutral when empty. Thus, the point defects can be classified as shallow level defects with their energy levels close to the $\mathrm{CB}$ or VB, or deep level defects with their energy levels away from the CB or VB edges. An understanding of point defect physics can be gained by combining theory and experiment [1].

In this article, the density of charged intrinsic defects, $\mathrm{N}_{\mathrm{id}}$, is determined by identifying the position of the intrinsic Fermi level in a semiconductor having defects from the band offset measurements of a MetalInsulator-Semiconductor (MIS) device interface. The intrinsic defects are charged deep level defects in a doped semiconductor. The method presented utilizes the physics of charge neutrality in a semiconductor leading to formulating the intrinsic Fermi level with an additional term due to $\mathrm{N}_{\mathrm{id}}$. Defect density calculations have been performed on $\mathrm{Si}, \mathrm{SiC}$, Diamond, and some compound semiconductors. The method is particularly able to determine very low defect density in Diamond, which otherwise is not possible by the existing techniques [1]. A limitation of this method is that in semiconductors like GaAs, where EL2 amphoteric defects pin the Fermi level to the middle of the bandgap, $\mathrm{N}_{\mathrm{id}}$ determination is not possible.

\section{Theory}

In general, the charge neutrality equation for a semiconductor material can be written as:

$$
\mathrm{n}-\mathrm{p}+\mathrm{N}_{\mathrm{A}}{ }^{-}-\mathrm{N}_{\mathrm{D}}{ }^{+}+\mathrm{N}_{\mathrm{id}}=0 \text {; }
$$

where, $\mathrm{n}$ is the density of conduction electrons, $\mathrm{p}$ is the density of valence holes, $\mathrm{N}_{\mathrm{A}}{ }^{-}$is the density of shallow acceptors, $\mathrm{N}_{\mathrm{D}}{ }^{+}$is the density of shallow donors, and $\mathrm{N}_{\mathrm{id}}$ is the intrinsic defects density of charged acceptor/donor deep traps that compensate the shallow donors/acceptors in a semiconductor. For an n-doped semiconductor, the equation will reduce to:

$$
\mathrm{n}-\mathrm{p}-\mathrm{N}_{\mathrm{D}}^{+}+\mathrm{N}_{\mathrm{id}}=0
$$

and further if the semiconductor is made intrinsic by removing $\mathrm{N}_{\mathrm{D}}{ }^{+}$, then the equation will reduce to:

$$
\mathrm{n}-\mathrm{p}+\mathrm{N}_{\mathrm{id}}=0
$$

This gives the equation:

$$
\mathrm{n}+\mathrm{N}_{\mathrm{id}}=\mathrm{p} .
$$

Solving the equation further,

$$
\ln \left(1+\mathrm{N}_{\mathrm{id}} / \mathrm{n}\right)=\ln (\mathrm{p} / \mathrm{n})
$$

The hole concentration $\mathrm{p}$ in a semiconductor is given as:

$$
p=N_{V} \exp \left(-\frac{E_{F}-E_{V}}{k T}\right),
$$

and the electron concentration $\mathrm{n}$ is given as: 


$$
n=N_{C} \exp \left(-\frac{E_{C}-E_{F}}{k T}\right)
$$

In equations (6) and (7), $\mathrm{N}_{\mathrm{C}}$ is the density of states in the conduction band, $\mathrm{N}_{\mathrm{V}}$ is the density of states in the valence band, $\mathrm{E}_{\mathrm{C}}$ is the bottom of the conduction band, $\mathrm{E}_{\mathrm{V}}$ is the top of the valence band, $\mathrm{E}_{\mathrm{F}}$ is the Fermi level in a semiconductor, $\mathrm{k}$ is the Boltzmann constant, and $\mathrm{T}$ is the temperature in Kelvin. Substituting equations (6) and (7) for $\mathrm{p}$ and $\mathrm{n}$ in equation (5) gives:

$$
\ln \left(1+\frac{N_{i d}}{n}\right)=\ln \left(\frac{N_{V}}{N_{C}}\right)+\frac{-E_{F}+E_{V}+E_{C}-E_{F}}{k T}
$$

Since this is an intrinsic material, therefore $n=n_{i}$ and $E_{F}$ is $E_{i}$. So the intrinsic Fermi level equation is given by:

$$
E_{i}=\frac{k T}{2} \ln \left(\frac{N_{V}}{N_{C}}\right)+\frac{E_{V}+E_{C}}{2}-\frac{k T}{2} \ln \left(1+\frac{N_{i d}}{n_{i}}\right) .
$$

Usually, $N_{V} \cong N_{C}$, and $\frac{E_{V}+E_{C}}{2} \quad$ is the middle of the bandgap for a semiconductor. Therefore,

$$
E_{i}=\frac{E_{g}}{2}-\frac{k T}{2} \ln \left(1+\frac{N_{i d}}{n_{i}}\right) \text {. }
$$

Equation (9) is the equation for the intrinsic Fermi level in a doped semiconductor having charged defects. The second term on the right hand side of equation (10) is the additional term due to the density $\mathrm{N}_{\mathrm{id}}$ of charged deep donor or acceptor traps in a doped semiconductor. The negative sign indicates that the energy due to $\mathrm{N}_{\text {id }}$ is above the midgap. It can be observed from this equation, that if the position of the intrinsic Fermi level in a semiconductor having defects is identified, then with the known bandgap of the semiconductor, the density of charged deep bulk defects in a doped semiconductor, $\mathrm{N}_{\mathrm{id}}$ can be determined. These bulk defects will also show up on the surface of the semiconductor sample, such that, if $\mathrm{N}_{\mathrm{id}}$ is high, then the surface density of defects will also be high, leading to pinning of the Fermi level at the interface with an insulator or metal as the case may be. Fermi level pinning would mean that the charge density at the interface cannot be changed by the application of bias.

\section{Results and Discussion}

The identification of $\mathrm{E}_{\mathrm{i}}$ from semiconductor/insulator band offsets and calculation results of charged defect density is discussed first. MIS characterization has been performed on $\mathrm{n}^{+}$polysilicon gated $\mathrm{n}$-channel silicon MOSFETs giving the $\mathrm{Si} / \mathrm{SiO}_{2} \mathrm{CBO}$ and $\mathrm{VBO}$ as $3.2 \mathrm{eV}$ and $4.6 \mathrm{eV}$ respectively. The bandgap of $\mathrm{SiO}_{2}$ is determined to be $8.9 \mathrm{eV}$ and the electron and hole conductivity effective masses in $\mathrm{SiO}_{2}$ are found to be $0.42 \mathrm{~m}$ and $0.58 \mathrm{~m}$, where $\mathrm{m}$ is the free electron mass [2]. For an effective electron mass of $0.42 \mathrm{~m}$, the $\mathrm{Si}_{/} / \mathrm{SiO}_{2}$ band offset from the intrinsic Fermi level is given as $8.9 \times 0.421 \cong 3.75 \mathrm{eV}$. The CBO of $3.2 \mathrm{eV}$ added to $0.55 \mathrm{eV}$ gives $3.75 \mathrm{eV}$. This $0.55 \mathrm{eV}$ addition brings the $\mathrm{CBO}$ relative to the intrinsic Fermi level in silicon. This is also $0.01 \mathrm{eV}$ less than midgap value for $\mathrm{Si}$, meaning that the $\mathrm{CBO}$ of the $\mathrm{Si} / \mathrm{SiO}_{2}$ interface relative to intrinsic Fermi level of silicon, which is nearly at midgap, is $3.75 \mathrm{eV}$. The band offset for all the semiconductor/SiO $\mathrm{interfaces}_{2}$ of $3.75 \mathrm{eV}$ will thus identify the intrinsic Fermi level position in any semiconductor. Table I below gives the band offsets at the interfaces of $\mathrm{Si}, \mathrm{SiC}$ and Diamond with $\mathrm{SiO}_{2}$ in columns 4 and $5 . \Delta \mathrm{E}_{\mathrm{c}}$ in column 4 is determined by subtracting $\mathrm{E}_{\mathrm{g}}$ from $\Phi_{\mathrm{e}}$, and $\Phi_{\mathrm{e}}$ is determined by the internal photoemission of electrons from the semiconductor valence band to the oxide conduction band. $\Delta \mathrm{Ec}$ subtracted from $3.75 \mathrm{eV}$ gives $\mathrm{E}_{\mathrm{c}}-\mathrm{E}_{\mathrm{i}}$ in column 6 , which is the position of the intrinsic Fermi level in that semiconductor.

Table I. The semiconductor bandgap $\left(\mathrm{E}_{\mathrm{g}}\right)$, the photoemission barrier $\left(\Phi_{\mathrm{e}}\right)$, the $\mathrm{CBO}$ and VBO, the position of intrinsic Fermi level $\left(\mathrm{E}_{\mathrm{i}}\right)$, the energy due to $\mathrm{N}_{\mathrm{id}}$, intrinsic carrier concentration $\left(\mathrm{n}_{\mathrm{i}}\right)$ and the intrinsic defect density $\left(\mathrm{N}_{\mathrm{id}}\right)$ for $\mathrm{Si}, \mathrm{SiC}$ and diamond interfaces with amorphous $\mathrm{SiO}_{2}\left(\mathrm{E}_{\mathrm{g}}=8.9 \mathrm{eV}\right)$.

\begin{tabular}{|l|l|l|l|l|l|l|l|l|}
\hline $\mathrm{sc}$ & $\mathrm{E}_{\mathrm{g}}(300 \mathrm{~K})$ & $\Phi_{\mathrm{e}}$ & $\Delta \mathrm{E}_{\mathrm{c}}$ & $\Delta \mathrm{E}_{\mathrm{v}}$ & $\mathrm{E}_{\mathrm{c}}-\mathrm{E}_{\mathrm{i}}$ & $\mathrm{E}_{\mathrm{i}}-\mathrm{E}_{\mathrm{g}} / 2$ & $\mathrm{n}_{\mathrm{i}}\left(\mathrm{cm}^{-3}\right)$ & $\mathrm{N}_{\mathrm{id}}\left(\mathrm{cm}^{-3}\right)$ \\
\hline $\mathrm{Si}$ & 1.12 & 4.27 & 3.2 & 4.6 & 0.55 & 0.01 & $1.5 \mathrm{E} 10$ & $1.5 \mathrm{E} 10$ \\
\hline 4H-SiC & 3.26 & 6.0 & 2.78 & 2.9 & 0.97 & 0.66 & $1.0 \mathrm{E}-08$ & $1.1 \mathrm{E} 14$ \\
\hline $6 \mathrm{H}-\mathrm{SiC}$ & 3.02 & 6.0 & 2.95 & 2.9 & 0.80 & 0.71 & $1.0 \mathrm{E}-6$ & $5.2 \mathrm{E} 17$ \\
\hline 3C-SiC & 2.38 & 6.0 & 3.6 & 2.9 & 0.15 & 1.04 & $1.5 \mathrm{E}-1$ & $1.8 \mathrm{E} 33$ \\
\hline 15R-SiC & 2.96 & 6.0 & 3.0 & 2.9 & 0.75 & 0.73 & $2.0 \mathrm{E}-6$ & $4.8 \mathrm{E} 18$ \\
\hline Diamond & 5.5 & 6.9 & 1.4 & 2.0 & 2.35 & 0.4 & $1.0 \mathrm{E}-26$ & $2.3 \mathrm{E}-13$ \\
\hline
\end{tabular}

Thus, column 6 provides the position of the intrinsic Fermi level below the conduction band of the semiconductors $\mathrm{Si}, \mathrm{SiC}$, and Diamond. From equation (10) it can be seen that the energy due to $\mathrm{N}_{\mathrm{id}}$ relative to $\mathrm{n}_{\mathrm{i}}$ is given in column 7. Given the $\mathrm{n}_{\mathrm{i}}$ values in column 8 , the $\mathrm{N}_{\mathrm{id}}$ concentrations in the semiconductors are calculated using equation (10) and presented in column 9. It can be observed that the key to finding the $\mathrm{N}_{\text {id }}$ volume density is identifying the intrinsic Fermi level position in a doped semiconductor/insulator interface. Here, $\mathrm{Si}$ and $\mathrm{SiC}$ samples are doped n-type and the diamond sample is doped p-type. 
A new method of calculating charged deep level defects density in doped semiconductors from the..

A literature survey of charged defect density calculations provides $\mathrm{N}_{\mathrm{id}}$ data for three of the six semiconductors in Table I: $\mathrm{Si}$ [3], 4H-SiC [4-5], and 6H-SiC [6]. These data match very well to the calculations in the Table and hence the author has the confidence in the theory and method of calculating $\mathrm{N}_{\mathrm{id}}$ presented in this article. Comparing the $\mathrm{N}_{\mathrm{id}}$ values for $\mathrm{Si}, \mathrm{SiC}$, and Diamond, it can be observed that $\mathrm{N}_{\mathrm{id}}$ in $\mathrm{SiC}$ is at least $10^{4}$ times more than in Si and very small in Diamond. Since the bulk defect density will be reflected at the interface also therefore it can be inferred that $\mathrm{SiC} / \mathrm{SiO}_{2}$ interface will have more defect states than $\mathrm{Si}$ and Diamond. This is also established by the MOS device study of $\mathrm{Si}, \mathrm{SiC}$ and Diamond. Si MOS study gives interface trap density $\left(D_{i t}\right)$ in the low $10^{11}$ order near conduction band (CB) [7], SiC MOS study gives $D_{i t}$ in the $10^{13}$ order near CB [8], and Diamond MOS has $\mathrm{D}_{\text {it }}$ in the low $10^{10}$ order near CB [9], and these values are all without any kind of interface passivation. It needs to be mentioned here that near conduction band means physically near the semiconductor/oxide interface on the semiconductor side. $\mathrm{SiC}$ is thus definitely more defective than $\mathrm{Si}$ and Diamond, although research efforts are underway to reduce $\mathrm{D}_{i t}$ in SiC MOS device to the level of Si MOS device [8]. It can be observed that Diamond has the best interface with the $\mathrm{SiO}_{2}$ having the least $\mathrm{N}_{\mathrm{id}}$.

In a charged semiconductor/ $\mathrm{SiO}_{2}$ interface, band offset measurements by photoemission techniques could be in error. This problem and its simple solution is discussed next. Thermal $\mathrm{SiO}_{2}$ grown on $\mathrm{Si}$ has small $\mathrm{D}_{\text {it }}$ of $10^{10} \mathrm{~cm}^{-2} \mathrm{eV}^{-1}$ after Hydrogen passivation, and a fixed positive charge density near the interface in the oxide of $10^{10} / \mathrm{cm}^{2}$. These values of densities are small and do not affect the internal photoemission measurements, even for ultrathin oxide of 2-4 $\mathrm{nm}$ [10]. Thin oxides with large charge density can cause band bending in the semiconductor of the semiconductor/oxide interfaces of $\mathrm{SiC} / \mathrm{SiO}_{2}$ [11] or Diamond/CVD $\mathrm{SiO}{ }_{2}$ [9]. Fixed positive charge can cause band bending inwards so as to cause accumulation in n-semiconductor and the VBO will be less than actual and the $\mathrm{CBO}$ will be more than actual. Fixed negative charge in the oxide will cause depletion in the n-semiconductor and the $\mathrm{CB}$ will bend upwards giving less than actual CBO and more than actual VBO. A similar analysis can be performed for the p-type semiconductor, where the fixed positive charge will cause depletion in the p-semiconductor and the fixed negative charge will cause accumulation in the p-semiconductor. A good review on internal photoemission explains this problem [12]. The remedy for this is to have a thick oxide of $20 \mathrm{~nm}$ or more such that the voltage required at the gate of the MIS device to compensate the fixed charges fall more across the oxide due to its higher resistance and less across the semiconductor, thus causing almost no band bending at the semiconductor surface. The literature provides support for this method on $\mathrm{SiC}_{\mathrm{SiO}}$ interfaces, where oxide thickness of greater than $20 \mathrm{~nm}$ [13], and $40 \mathrm{~nm}$ $[11,14]$ were taken in the samples.

Another review article by Afanasev [15] provides band offset data for various compound semiconductors relevant to the electronic industry with amorphous $\mathrm{Al}_{2} \mathrm{O}_{3}$, given in Table 1 of reference [15]. The bandgap of $\mathrm{Al}_{2} \mathrm{O}_{3}$ is $6.1 \mathrm{eV}$ and the MIS structures utilize a thickness of $20 \mathrm{~nm}$ to eliminate the problems of band bending in charged semiconductor/insulator interfaces. The $\mathrm{CBO}$ of $\mathrm{Si} / \mathrm{Al}_{2} \mathrm{O}_{3}$ interface from the intrinsic Fermi level of $\mathrm{Si}$ is $2.65 \mathrm{eV}$ forming the control data for identifying the intrinsic Fermi level in other semiconductors. The Table II below provides the calculated $\mathrm{N}_{\mathrm{id}}$ values for the compound semiconductors and Ge, excluding GaAs and GaSb which exhibit Fermi level pinning and is indicated by FLP in the table. Once again, column 6 provides the position of intrinsic Fermi level below the $\mathrm{CB}$ by subtracting $\Delta \mathrm{E}_{\mathrm{c}}$ in column 4 from $2.65 \mathrm{eV}$. It can be noticed that the intrinsic Fermi level for InGaAs, InAs, and InSb lie in the CB and have very large $\mathrm{N}_{\mathrm{id}}$ values. This indicates that electron mobility will be severely degraded in devices made from these semiconductors. $\mathrm{K}$. Xu et al [16] have performed band offset measurements of InP with atomic layer deposited $\mathrm{Al}_{2} \mathrm{O}_{3}$ in 2013. There work provides the photoemission barrier $\left(\Phi_{\mathrm{e}}\right)$ of $3.5 \mathrm{eV}$, thus correcting the $\mathrm{CBO}$ data of Afanasev [15] to $2.15 \mathrm{eV}$ in column 4. The $\mathrm{N}_{\mathrm{id}}$ value for $\mathrm{GaP}$ matches very well to the calculations performed by DLTS measurements in the literature [17]. This provides confidence in the calculatd $\mathrm{N}_{\text {id }}$ values for other compound semiconductors and Ge in Table II by the new method in this article. It can be observed in the table below that $E_{i}-E_{g} / 2$ is negative for Ge indicating that energy due to $N_{i d}$ in equation (10) becomes positive and is thus in the lower half of the bandgap.

Table II. The semiconductor bandgap $\left(\mathrm{E}_{\mathrm{g}}\right)$, the photoemission barrier $\left(\Phi_{\mathrm{e}}\right)$, the CBO and VBO, the position of intrinsic Fermi level $\left(\mathrm{E}_{\mathrm{i}}\right)$, the energy due to $\mathrm{N}_{\mathrm{id}}$, intrinsic carrier concentration $\left(\mathrm{n}_{\mathrm{i}}\right)$ and the intrinsic defect density $\left(\mathrm{N}_{\mathrm{id}}\right)$ for several compound semiconductor interfaces with a- $\mathrm{Al}_{2} \mathrm{O}_{3}\left(\mathrm{E}_{\mathrm{g}}=6.1 \mathrm{eV}\right)$.

\begin{tabular}{|l|l|l|l|l|l|l|l|l|}
\hline $\mathrm{sc}$ & $\mathrm{E}_{\mathrm{g}}(300 \mathrm{~K})$ & $\Phi_{\mathrm{e}}$ & $\Delta \mathrm{E}_{\mathrm{c}}$ & $\Delta \mathrm{E}_{\mathrm{v}}$ & $\mathrm{E}_{\mathrm{c}}-\mathrm{E}_{\mathrm{i}}$ & $\mathrm{E}_{\mathrm{i}}-\mathrm{E}_{\mathrm{g}} / 2$ & $\mathrm{n}_{\mathrm{i}}\left(\mathrm{cm}^{-3}\right)$ & $\mathrm{N}_{\mathrm{id}}\left(\mathrm{cm}^{-3}\right)$ \\
\hline $\mathrm{Si}$ & 1.12 & 3.25 & 2.1 & 2.9 & 0.55 & 0.01 & $1.5 \mathrm{E} 10$ & $1.5 \mathrm{E} 10$ \\
\hline $\mathrm{Ge}$ & 0.67 & 2.85 & 2.2 & 3.3 & 0.45 & -0.11 & $2.0 \mathrm{E} 13$ & $9.5 \mathrm{E} 16$ \\
\hline $\mathrm{GaAs}$ & 1.42 & 3.45 & 2.0 & 2.7 & 0.65 & 0.06 & $2.1 \mathrm{E} 06$ & FLP \\
\hline $\mathrm{In}_{0.53} \mathrm{Ga}_{0.47} \mathrm{As}$ & 0.74 & 3.45 & 2.7 & 2.7 & -0.05 & 0.42 & $6.3 \mathrm{E} 11$ & $6.7 \mathrm{E} 25$ \\
\hline $\mathrm{InAs}$ & 0.35 & 3.45 & 3.1 & 2.7 & -0.45 & 0.625 & $1.0 \mathrm{E} 15$ & $7.5 \mathrm{E} 35$ \\
\hline $\mathrm{GaP}$ & 2.24 & 4.1 & 1.8 & 2.0 & 0.85 & 0.27 & $2.7 \mathrm{E} 06$ & $2.8 \mathrm{E} 15$ \\
\hline $\mathrm{InP}$ & 1.35 & 3.5 & 2.15 & 2.6 & 0.50 & 0.175 & $1.3 \mathrm{E} 07$ & $9.1 \mathrm{E} 12$ \\
\hline $\mathrm{GaSb}$ & 0.73 & 3.05 & 2.3 & 3.05 & 0.35 & 0.015 & $1.5 \mathrm{E} 12$ & FLP \\
\hline $\mathrm{InSb}$ & 0.17 & 3.05 & 2.9 & 3.05 & -0.25 & 0.335 & $2.0 \mathrm{E} 16$ & $3.1 \mathrm{E} 27$ \\
\hline
\end{tabular}




\section{Conclusions}

The present article gives a new method of calculating the density of charged deep level defects in the doped semiconductors by identifying the intrinsic Fermi level in any semiconductor from the band offset measurements of MIS devices. The method is able to give very low defect densities that are not possible by the existing methods, such as in Diamond, $\mathrm{Si}$, and InP. A limitation of this method is that it cannot be used in semiconductors whose Fermi level is pinned to the middle of the bandgap such as in GaAs or GaSb. The article also gives a new equation of the intrinsic Fermi level in semiconductors with an added term due to the density of charged intrinsic defects.

\section{References}

[1] A. Alkauskas, M.D. McCluskey, and C.G. Van de Walle, "Tutorial: Defects in semiconductors- Combining experiment and theory", J. Appl. Phys., vol. 119, 181101, 2016.

[2] R.K. Chanana, "N-Channel silicon MOSFET as a device to characterize MIS structures by the BOEMDET technique", IOSR-J. Appl. Phys., vol. 7, Issue-4, pp.17-25, Jul-Aug, 2015.

[3] E.G. Seebauer, M.C. Kratzer, "Fundamentals of defect ionization and transport" in Charged Semiconductor defects-Structure, thermodynamics and diffusion, Springer, 2009, pp. 5-34

[4] E. Janzen, N.T. Son, B. Magnusson, A. Ellison, “Intrinsic defects in high-purity SiC”, Microelectronic Engineering, vol.83, pp. 130-134, 2006.

[5] P.B. Klein, B.V. Shanabrook, S.W. Huh, A.Y. Polyakov, M. Skowronski, J.J. Sumakeris, and M.J. O’ Loughlin, “Life-time limiting defects in n- 4H-SiC epilayers", Appl. Phys. Lett., vol.88, 052110, 2006.

[6] P. Kaminski, M. Kozubal, K. Grasza, and E. Tymicki, "Deep-level defects in nitrogen-doped 6H-SiC grown by PVT method", MRS online proceedings library, 1069, Jan 2011.

[7] E.H. Nicollian, J.R. Brews, "Control of oxide charges" in MOS (Metal Oxide Semiconductor) Physics and Technology, John Wiley and Sons, 1982, p.794.

[8] G.Y. Chung, C.C. Tin, J.R. Williams, K. McDonald, M. Di Ventra, S.T. Pantelides, L.C. Feldman, and R.A. Weller, "Effect of nitric oxide annealing on the interface trap densities near the band edges in the 4H-Polytype of Silicon Carbide", Appl. Phys. Lett., vol. 76, pp. 1713-15, Mar. 2000

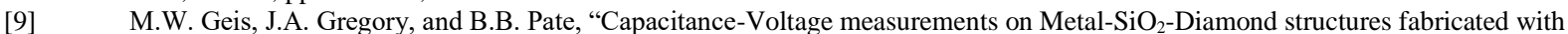
(100)- and (111)- oriented substrates, IEEE Trans, on Electron Devices, vol. 38, pp.619-626, Mar. 1991.

[10] E. Bersch, S. Rangan, R.A. Bartynski, E. Garfunkel, E. Vescovo, "Band offsets of ultrathin high-K oxide films with Si", Physical Review B., vol. 78, 085114, 2008.

[11] H. Watanabe, and T. Hosoi, "Fundamental Aspects of Silicon Carbide oxidation", in Physics and Technology of Silicon Carbide, InTech, pp. 235-250, 2013.

[12] V.V. Afanasev, and A. Stesmans, "Internal photoemission at interfaces of high-K insulators with semiconductors and metals", Applied Physics Reviews, vol. 102, 081301, 2007.

[13] V.V. Afanasev, M. Bassler, G. Pensl, M.J. Shulz, and E.S. von Kamienski, "Band offsets and electronic structure of SiC/SiO 2 interfaces", J. Appl. Phys. Vol. 79, pp. 3108-3114, Mar. 1996.

[14] R.K. Chanana, "Determination of hole effective mass in $\mathrm{SiO}_{2}$ and $\mathrm{SiC}$ conduction band offset using Fowler-Nordheim tunneling characteristics across metal-oxide-semiconductor structures after applying oxide field corrections", J. Appl. Phys. Vol. 109, $104508,2011$.

[15] V.V. Afanasev, "Electron band alignment at interfaces of semiconductors with insulating oxides: An internal photoemission study", Advances in Condensed Matter Physics, vol. 2014, pp. 1-30, Hindawi Publishing Corporation, 2014.

[16] K. Xu, H. Sio, O.A. Kirilov, L. Dong, M.Xu et al., "Band offset determination of atomic- layer-deposited $\mathrm{Al}_{2} \mathrm{O}_{3}$ and $\mathrm{HfO}_{2}$ on $\mathrm{InP}$ by internal photoemission and spectroscopic ellipsometry", J. Appl. Phys. Vol. 113, 024504, 2013.

[17] S. Das, S.K. Chaudhuri, and K.C. Mandal, "Deep level studies in high-resistive Gallium Phosphide single crystals", ECS J. Solid State Science and Technology, vol. 5, Issue-4, pp. 3059-3063, 2016. 